\title{
Larval reef fish could use odour for detection, retention and orientation to reefs
}

\author{
Jelle Atema ${ }^{1, *}$, Michael J. Kingsford ${ }^{2}$, Gabriele Gerlach ${ }^{3}$ \\ ${ }^{1}$ Boston University Marine Program, Marine Biological Laboratory, Woods Hole, Massachusetts 02543, USA \\ ${ }^{2}$ School of Marine Biology and Aquaculture, James Cook University, Queensland 4811, Australia \\ ${ }^{3}$ Marine Biological Laboratory, Woods Hole, Massachusetts 02543, USA
}

\begin{abstract}
While evidence is mounting that larval reef fish are active participants in the process of dispersal and settlement, the sensory and behavioural mechanisms by which these fishes disperse and return from their oceanic phase to the reefs remain unknown. On One Tree Island (Great Barrier Reef, Australia), we tested freshly collected animals in a large choice-flume on the shore. Here, we present the first evidence that larval reef fish (primarily apogonids) approaching the time of settlement are capable of detecting differences between ocean and lagoon water and prefer lagoon water. We also demonstrate that they sniff actively with well-innervated noses and that attraction to lagoon water was not affected by warmer or colder temperatures. We conclude that they used chemical signals to orient toward lagoon water. Finally, we describe ebb tide plumes of lagoon water that extend many kilometers from reefs. Such plumes could provide chemosensory cues for dispersal and settlement stages of reef fish as they develop swimming efficiency. We argue that fishes may imprint to reef odour as embryos and/or early larvae and that this could facilitate both retention near the natal reef and navigation toward reefs from greater distances.
\end{abstract}

KEY WORDS: Fish migration · Dispersal $\cdot$ Larval reef fish · Odour plume $\cdot$ Apogonids $\cdot$ Cardinal fish · Coral reef conservation

Resale or republication not permitted without written consent of the publisher

\section{INTRODUCTION}

Most coral reef fishes have a larval dispersal phase during which they can travel considerable distances in the pelagic environment. After a few weeks to months they return to a reef to settle. The initial plankton concept of fish larvae led to dispersal models driven entirely by advection (e.g. Williams et al. 1984). However, computational models have shown convincingly that advection alone cannot explain recruitment success of fish larvae (e.g. Wolanski et al. 1997, Armsworth 2000, Cowen et al. 2000). Local retention leading to 'self-recruitment' has been suggested for isolated oceanic islands (e.g. Lobel \& Robinson 1986, Boehlert \& Mundy 1993, Robertson 2001) and shown

*E-mail: atema@bu.edu for more connected reef systems (Jones et al. 1999, Swearer et al. 1999). Also, genetic data on population substructuring support the notion that marine dispersal is more segregated than once believed (Planes et al. 1993).

This evidence points to active participation in the dispersal and recruitment processes by the pelagic stages of reef-fish larvae. The late larval stages develop powerful swimming capabilities (Kingsford 1988, 2001, Leis 1991, Fisher et al. 2000) with whichin still water-they could cover distances of tens of kilometers even without feeding (Leis \& Carson-Ewart 1997, Stobutzki \& Bellwood 1997). Some species can maintain swimming speeds of $30 \mathrm{~cm} \mathrm{~s}^{-1}$ for several days (Fisher et al. 2000). This behavioural evidence suggests that presettlement reef fish contribute actively to the process of settlement (see reviews by Montgomery et al. 2001, Kingsford et al. 2002). Either 
they maintain themselves in the reef vicinity or they manage to arrive from greater distances. It is immediately obvious that choosing the right current for transport will save energy. Current directions vary with depth and time. Finding the proper depth may turn out to be essential for successful recruitment (Cowen et al. 2000). Late-stage larvae have the visual capability to feed at considerable depths (Job \& Bellwood 2000) where they may find advantageous currents. However, it remains unknown how they determine which current is advantageous.

Indeed, the sensory mechanisms necessary for choice of currents or more complex horizontal and vertical navigation behaviour remain speculative. Pelagic stage reef fishes have well-developed sense organs (J. Atema pers. obs.) with specific ontogenetic trajectories (vision, Job \& Bellwood 2000; olfaction, Arvedlund et al. 2000). Three of the most likely ways to detect reefs include sound, chemical signals and temperature. Sound is a plausible sensory cue causing directional responses of reef fish larvae captured and released at distances of kilometers from reefs (Leis et al. 1996, Stobutzki \& Bellwood 1998, Tolimieri et al. 2000). Olfaction influences settlement behaviour at small spatial scales (Sweatman 1988, Elliott et al. 1995, Arvedlund \& Nielsen 1996). Olfactory homing of salmonids (Dittman et al. 1996) is an example of chemical signals used by fish at large spatial scales. Temperature, particularly with regard to warm reef plumes, has been suggested as a logical cue (Doherty et al. 1996), but to our knowledge no evidence for its use in orientation exists.

Our study was initiated to test olfactory involvement in the recognition of reef water, particularly in conditions where distinct plumes emerge, such as from One Tree Island Reef (OTI) in the Great Barrier Reef. For this study we have chosen to focus primarily on apogonids, including Apogon doederleini, A. guamensis and Cheilodipterus quinquelineatus. Settlement stage apogonids of these species were common in our catches (Leis \& Rennis 1983, Kingsford 2001) and swam well in our experimental flume. Adult apogonids, including 2 species we used, showed impressive site fidelity and homing ability. Marnane (2000) tagged adult cardinal fishes and found that they remained within $\sim 36$ to $79 \mathrm{~cm}$ of their initial resting positions within One Tree Reef lagoon: this was the case for over $8 \mathrm{mo}$ in A. doederleini and over 16 mo in C. artus and C. quinquelineatus. Adults could relocate their point of collection within $3 \mathrm{~d}$ after having been displaced for up to $2 \mathrm{~km}$. Apogonid eggs are brooded for up to $19 \mathrm{~d}$ in their father's mouth (Vagelli 1999). This should facilitate imprinting on the natal environment. The pelagic stage lasts for a few weeks. From hatching until settlement apogonid larvae Sphaeramia nematoptera grow from $\sim 3$ to $\sim 12 \mathrm{~mm}$ total length with critical swimming speeds increasing from $\sim 2$ to $\sim 15 \mathrm{~cm} \mathrm{~s}^{-1}$ (Fisher et al. 2000). Late pelagic stages of apogonids are quite capable swimmers with mean critical swimming speeds of $\sim 10 \mathrm{~cm} \mathrm{~s}^{-1}$ for $\sim 10 \mathrm{~h}$. Maximum endurance observed in a treadmill flume was $36 \mathrm{~h}$ swimming at $13.5 \mathrm{~cm} \mathrm{~s}^{-1}$, equivalent to a distance of $\sim 17 \mathrm{~km}$. Even at settlement, apogonids are not among the strongest swimmers such as pomacentrids, and especially acanthurids (Stobutzki \& Bellwood 1997, Fisher et al. 2000). In light-trap catches, apogonid larvae appear more commonly at greater depths (9 to $16 \mathrm{~m}$, Fisher \& Bellwood 2002). They also exhibit greater light sensitivity (Job \& Bellwood 2000), suggesting adaptation to deeper water.

Settlement in Apogon doederleini and Cheilodipterus quinquelineatus at OTI appears to take place in 2 phases: first to sand-rubble habitat, and then to continuous reef after some days of feeding and increasing mobility (Finn \& Kingsford 1996).

In his recruitment model, Armsworth (2000) considered 4 important categories of behavioural/sensory capabilities in reef fish larvae: strong and weak swimmers and sensory cues that are either dependent on current or not. He argued that powerful swimmers such as acanthurids could come from greater distances using both current-dependent and -independent sensory cues, and that weak swimmers such as apogonids should have evolved sensory mechanisms to stay near the reef. We will argue that odour might provide a mechanism to choose appropriate currents that could lead them to, or keep them near, the reef. Here, we report on the results of 3 experimental approaches, oceanography, behaviour, and olfactory anatomy, providing evidence that after weeks 'at sea', settlement stage apogonids and perhaps other reef fish could use characteristic reef odour in the process of finding appropriate water currents and settlement habitat.

\section{MATERIALS AND METHODS}

Field work and behavioural experiments. Conspicuous ebb-tide plumes were observed from boats, and their shape was determined using GPS while driving the boat along visually obvious frontal margins (Fig. 1). The shape of the plumes was estimated 3 to $4 \mathrm{~h}$ after the high tide. Temperature signatures were measured with data loggers (sampling interval $0.5 \mathrm{~min}$ ) for time series of temperature pulses and with a conductivity, temperature and depth device (CTD) for depth profiles (Figs. 2 \& 3). The CTD data were collected in and out of an ebb-tide plume at 17:00 h on January 22, 1999. Data loggers were also positioned at 1 and $10 \mathrm{~m}$ depth during February 1998. Presettlement fishes were collected in channel nets with large $(\sim 51)$ cod ends to keep them 


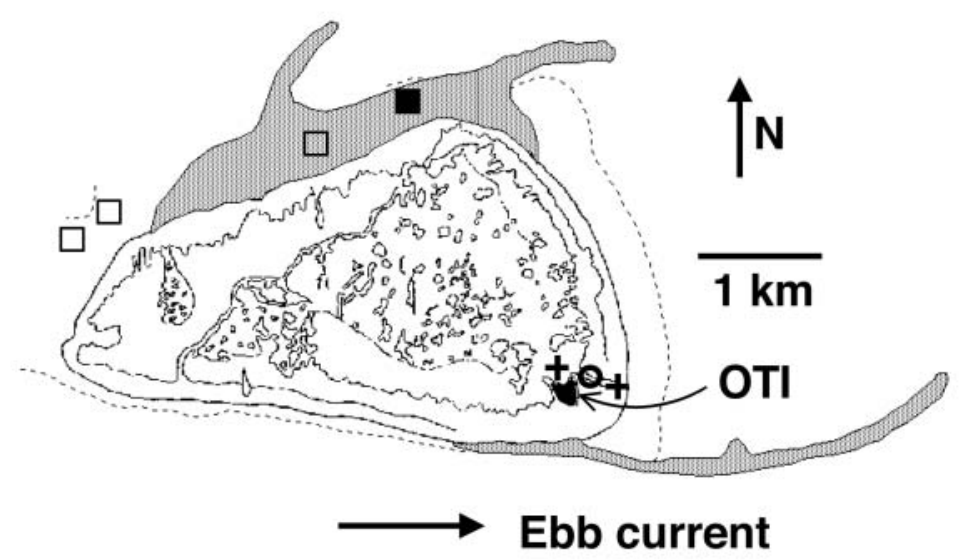

Fig. 1. One Tree Reef study area surrounding One Tree Island (OTI: $24^{\circ} 30^{\prime} \mathrm{S}, 152^{\circ} \mathrm{E}$ ) on the outer edge of the Southern Great Barrier Reef, just south of the Tropic of Capricorn, showing ebb-tide plumes (grey) in conditions of NW winds, (January 27, 1997). Position of light traps, with $(\square)$ or without $(\square)$ a temperature logger array, and channel nets (O), locations of lagoon and reef crest water intakes (+) used for choice tests, are shown. Dashed line: $20 \mathrm{~m}$ depth isopleth. Continental shelf drops immediately east of OTI

alive; other fishes were collected in light traps on the reef slope (procedures and equipment described in Doherty 1987, Kingsford \& Finn 1997 and Kingsford 2001).

Water choice experiments were done using water collected from 2 locations (Fig. 1). Lagoon water was pumped from the lagoon during ebb to low tides, when the OTI ponding lagoon is practically isolated from the surrounding ocean circulation. As plume water consists of an outpouring of lagoon water, we considered lagoon water appropriate for our intended use, as collecting actual plume water in the quantities needed was impractical. Ocean water was pumped from the reef crest during flood tides as typically easterly winds drove floodwaters from the open ocean into the OTI lagoon. The collection of ocean water far away from the reef crest would also have been impractical and unnecessary for the purposes of our experiments. Water was stored in two separate 20001 tanks for 0 to $30 \mathrm{~h}$ before being used in experiments when it was gravity-fed into two 1701 constant header tanks to maintain constant flow leading into the 2 upstream channels of the test flume. At the appropriate times, water from the header tanks was stopped or switched manually between the 2 sides of the test flume.

The test area was $61 \times 50 \mathrm{~cm}$ corresponding to $>40$ body lengths of experimental fish. Water depth was 5.5 to $6.5 \mathrm{~cm}$ ( $\sim 12$ body depths) at a flow speed of $6 \mathrm{~cm} \mathrm{~s}^{-1}$ (through a $1 \%$ downstream tilt of the flume) corresponding to a volume flow of $\sim 1.5 \mathrm{l} \mathrm{s}^{-1}$. Flow balance between sides, and separation of the 2 water masses in the test area were visualised with 2 different dyes before and after each experiment. In all cases, flow and turbulence appeared equal on both sides. The flume allowed us to present 2 masses of moving water separated by a sharp boundary which the fish could cross at will. When temperature differences between water masses were negligible the separation boundary remained vertical and centred. When present, temperature differences caused colder (denser) water to slide gradually underneath the warmer water resulting in a slowly increasing area of overlap near the downstream end of the flume. With extreme temperature differences $\left(3^{\circ} \mathrm{C}\right)$ this most downstream area was about $50 \mathrm{~cm}$ wide (Fig. $4 \mathrm{e}$ ).

We adopted an experimental design that allowed us to extract responses to differences in water chemistry and temperature, while controlling for water flow and unintended preferences for either side of the tank. We were constrained by 'the catch of the day', i.e. the species and numbers of fish caught varied from day to day. Another constraint was the amount of lagoon and ocean water that could be stored. The majority of

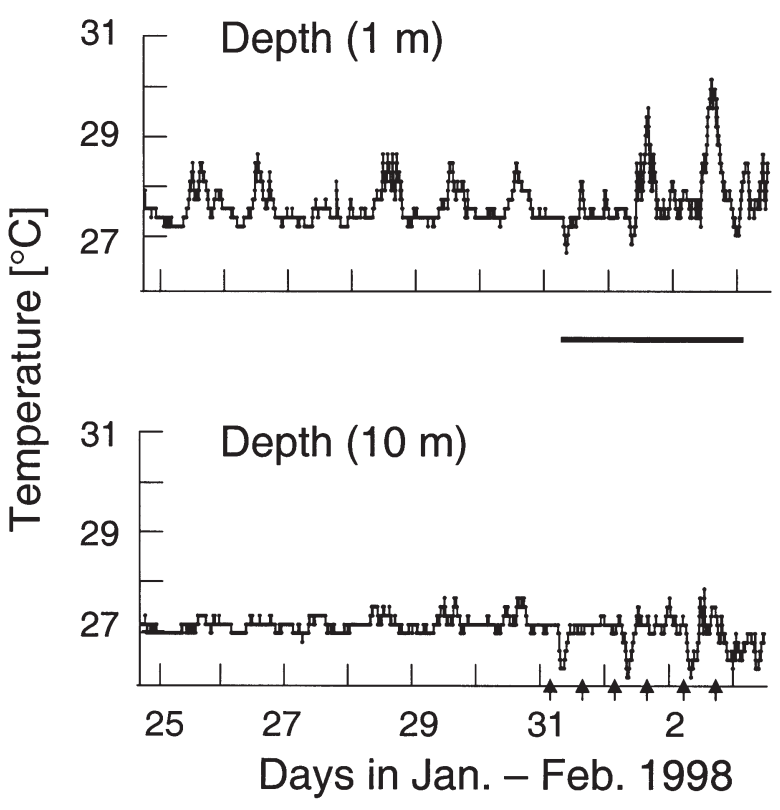

Fig. 2. Temperature traces from data loggers at 1 and $10 \mathrm{~m}$ depths showing warm-water spikes at tidal intervals (January 24 to February 3, 1998). Spike coincidence between 1 and $10 \mathrm{~m}$ traces is clearest during the later days. Amplitude variance may be due to winds. Warm spike amplitudes at $1 \mathrm{~m}$ increased as afternoon ebb tides shifted later in the day, allowing for greater lagoon heating and warmer plume water. During the same period (black bar January 31 to February 2, 1998) early morning ebb tides-after a cool nightresulted in the advection of cool water from the lagoon (greatest amplitude at $10 \mathrm{~m}$ ). Arrows on $x$-axis indicate timing of low tide during this period 


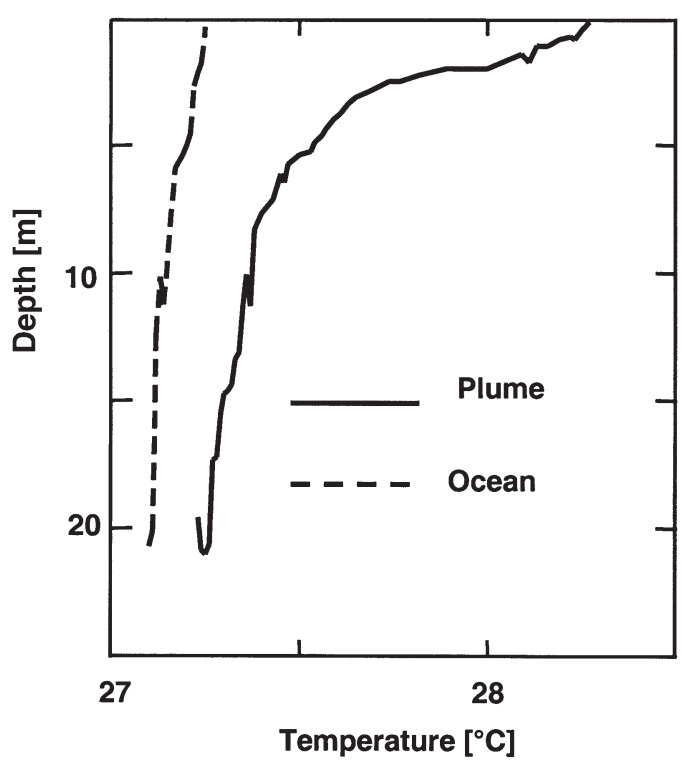

Fig. 3. Temperature-depth profiles within (solid line) and outside (broken line) a warm surface plume during ebb tide late afternoon (January 25, 1999)

our experiments were done with groups of 1 to 13 apogonids, including Apogon doederleini, A. guamensis, Apogon sp. (based on morphology and consistent pigmentation) and Cheilodipterus quinquelineatus. In January, when settlement occurs, larval apogonids (10 to $15 \mathrm{~mm}$ standard length [SL]) were collected primarily in channel nets as they flooded over the reef crest into the lagoon (Fig. 1). Others were caught with light traps tethered 15 to $20 \mathrm{~m}$ above the substratum outside the reef. Detailed comparisons of the size of presettlement and newly settled apogonids lead Finn \& Kingsford (1996) to conclude that fishes in nets were presettlement forms, many of which were at the 'potential settler' stage. We considered all fishes collected in light traps and those caught in channel nets to be at presettlement stages and large enough to settle (Kingsford \& Finn 1997). No suitable habitat for small apogonids occurred upcurrent of the nets, further suggesting that contamination from postsettlement forms was unlikely. We also caught many pomacentrids and carried out our experimental work on some (Pomacentrus coelestis, P. amboinensis, P. bankenensis), but they appeared less comfortable in the flume environment leading us to focus on apogonids.

We acclimated the fish in the test area for at least 10 minutes in standing water from lagoon or ocean sources (designated as: $\mathrm{L}=$ lagoon, $\mathrm{O}=$ ocean, $\mathrm{X}=$ no flow; pairs of let- ters indicate left and right sides of the tank, e.g. XL denotes Lagoon water with no flow on left, Lagoon water flowing on right; LO denotes Lagoon water flowing on left, Ocean water flowing on right). Each experiment started with a 3 min observation in the acclimation water (Treatment 1: XX). For most experiments, this was lagoon water; in some cases acclimation was in ocean water. This was followed by a series of 3 treatments (nos 2 to 4 , each of 3 min duration) to measure the influence of water flow on side preference under constant source conditions and to further acclimate the animals to the tank conditions as follows: LL, LX, XL. It should be noted that a real 'no flow' treatment only existed when both sides had no flow (XX); when one side flowed (e.g. XL), the current pattern in the observation area became complex with current fanning into the 'no flow' side. In ocean acclimated tests the 3 flow treatments were OO, OX, XO. We then presented a series of water sources under conditions of constant flow but different or identical water chemistry: Treatments 5 to $11-\mathrm{LL}, \mathrm{OL}, \mathrm{LO}, \mathrm{LL}, \mathrm{LO}, \mathrm{OL}$, LL. In ocean acclimated tests, $\mathrm{L}$ and $\mathrm{O}$ were exchanged. We kept track of how and where the test fish were caught and how they were acclimated, as this may affect the results.

Temperature differences between $\mathrm{L}$ and $\mathrm{O}$ (dictated by nature) were continuously measured and varied unpredictably between experiments allowing us to assess its influence using regression analysis. We concluded the series with 3 min of zero flow (Treatment 12: XX). For data analysis we used only the 4 observations during the last minute of each 3 min test condition, to allow the fish time to express side preference by swimming, and thus sampling, across the centre line.

We calculated the number of fish that changed to the lagoon side during the 3rd minute of the new condi-

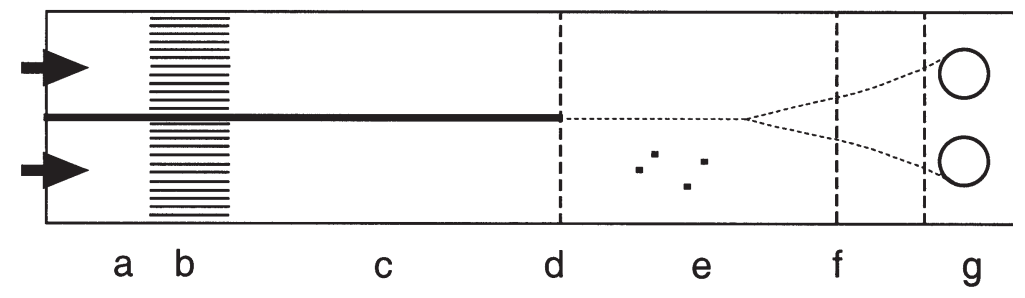

Fig. 4. Choice flume drawn to scale: overall size $240 \times 50 \mathrm{~cm}$, water depth $\sim 6 \mathrm{~cm}$. (a) Water inflow compartment; left and right side inflows (arrows) are exchanged by switching 2 hoses manually; (b) collimator of packed soda straws to homogenize turbulence; (c) barrier-separated channels to further laminate flow; (d) upstream fine mesh $(0.5 \mathrm{~mm})$ net to contain test animals; (e) $61 \times 50 \mathrm{~cm}$ test area where left- and right-side flows remain separated without barrier (fine dotted centre line; see text for detail); gradually separating centre line indicates downstream area where cooler water slid underneath warmer water in tests where ocean and lagoon water were at greatly different temperatures; ( $\mathbf{\square})$ scale of fish sizes used (10 to $12 \mathrm{~mm} \mathrm{SL}$ ); (f) down stream containment net; (g) drain area via perforated standpipes 
tion. This value became positive if more fish chose to the lagoon side and negative if more fish chose the ocean side. Water quality was switched between sides 6 times during each experiment. For each experiment the mean value of the 6 responses to switching between lagoon and ocean water was calculated (Treatments 5 to 11). The distribution of these values was tested in a Wilcoxon's signed-rank test using the null hypothesis that no change in distribution would occur after the water switch. To test for effects of flow we compared the distribution of fish in experimental treatments where water quality did not change (Treatments 1 to 5). Statistical analyses were done using the program JMP (SAS Institute 1995).

Olfactory system. Nasal ventilation was observed in live, unanaesthetized fish in a petri dish under a dissecting microscope: a small drop of methylene blue dye was pipetted near the anterior (incurrent) naris so that it was sucked into the olfactory sac and blown out of the posterior (excurrent) naris. The morphological description of the olfactory system is based on fine dissection of 10 fresh and fixed fishes used in behavioural experiments and on histological examination of 4 specimens. For histology, 2 late stage pelagic larvae of each of 2 experimental species (Apogon guamensis, 10 and $11 \mathrm{~mm} \mathrm{SL} ;$ A. doederleini, 10.5 and $12 \mathrm{~mm} \mathrm{SL}$ ) were fixed in $\sim 5 \%$ formalin for several months. They were decalcified (CalEx, Fisher), dehydrated in ethanol and t-butyl alcohol series, infiltrated and embedded in Paraplast (Fisher), and sectioned transversely at $8 \mathrm{um}$. Sections were stained using the HBQ stain (celestine blue, Mayers hematoxylin, alcian blue, direct red; Hall 1986) in order to visualise epithelia and elements of the cranial skeleton in the vicinity of the olfactory sac.

\section{RESULTS}

\section{Plume analysis}

Conspicuous turbidity plumes extend from OTI on ebb tides. These plumes have been plotted on 15 occasions over a $5 \mathrm{yr}$ period (1995-2000), 1 to $2 \mathrm{~h}$ after high tide; their position varied little, probably due to forcing of the tidal flow by underwater topography (Wolanski 1994). GPS positions indicate that plumes extend about $1.6 \mathrm{~km}$ from the reef crest on the northern tip of the island and 3 to $4 \mathrm{~km}$ on the eastern side (Fig. 1). Wind direction affects the plumes; the plume on the eastern side was not present during winds from the southeast.

Data loggers at $1 \mathrm{~m}$ and $10 \mathrm{~m}$ below the surface showed that diurnal plumes were warm and therefore floated (Fig. 2). The amplitude of temperature peaks was greatest when ebb tides were late in the afternoon. Water of the ponding lagoon warmed and was advected out on the ebb tide. In contrast, if the lagoon cooled while ponding overnight then relatively cool waters were advected out on the ebb. These cool plumes sank, and appeared as cool spikes primarily on the $10 \mathrm{~m}$ temperature logger (Fig. 2). The thermal signal of warm water plumes was weak at $10 \mathrm{~m}$, indicating that the plumes rarely made it to that depth. CTD profiles in and outside of a late-afternoon ebb-tide plume indicated that the plume extended 5-7 m below the surface; in this case it was about $1^{\circ} \mathrm{C}$ warmer than surrounding waters (control profile outside of the plume and below 10 m, Fig. 3).

On the water surface, plumes were generally smoother than ocean waters, presumably due to mucilage from corals and other large organic molecules from the lagoon (Johannes 1967, Deacon 1979, Crossland 1987). The plume features of OTI are not unique to ponding lagoons; observations from $300 \mathrm{~m}$ by helicopter showed similar turbidity plumes emerging from non-ponding lagoons of Sykes and Heron Reefs adjacent to OTI (M. J. Kingsford pers. obs.).

\section{Preference for lagoon water}

In 33 experiments with groups of 1 to 13 apogonids, initial left/right distribution (XX, Treatment 1) was close to $50 \%$ with individual fish moving occasionally from side to side; there was no distinct schooling. Bilateral flow (Treatment 2) resulted in upcurrent orientation, presumably based on optomotor response. In Treatments 3 to 5 where flow changed unilaterally but water quality remained the same, no significant side change was observed $(2.8 \pm 3.9 \%$, Table 1a). Although statistically not significant, the rather strong $(10.5 \%)$ flow response of pomacentrids is noteworthy.

In odour choice-tests (Treatments 5 to 11, where water source changed but flow conditions were always equal) $8.0 \pm 3.6 \%$ of the apogonids moved to the side of lagoon water (Table 1b). Therefore, these fish discriminated between water sources and significantly preferred lagoon water over ocean water (Wilcoxon's 2 -tailed signed-rank test, $t=2.2, \mathrm{p}=0.036$ ). Pomacentrids showed no odour choice, at least with our small sample size. Temperature difference between the left and right side of the flume had no influence on how many fish were present on each side (Spearman's rank correlation RS $=-0.037, p=0.44 ;$ Fig. 5). Neither colder nor warmer lagoon water made a significant difference.

In 21 of the 33 experiments above, fish were caught in crest nets and stored (acclimated) for 1 to $24 \mathrm{~h}$ in lagoon water. This group of lagoon trapped and acclimated animals (LL) showed a 9.5\% lagoon water preference (Table 1b). In 12 experiments, fishes were 
Table 1. (a) Fish choice for flow or no flow conditions. Fish were trapped and acclimated under different conditions: trapped and acclimated in lagoon water (LL), trapped and acclimated in ocean water (OO); trapped in lagoon and acclimated in ocean water (LO), trapped in ocean and acclimated in lagoon water (OL). Apo: apogonids; Pom: pomacentrids $($ Apo all $=\mathrm{LL}+\mathrm{OO}+\mathrm{LO}+\mathrm{OL}) ; \mathrm{n}=$ number of experiments (individuals per experiment ranged from 1 to 13). Preference was tested statistically by a Wilcoxon's 2-tailed signed-rank test, ${ }^{*} \mathrm{p} \leq 0.05,{ }^{* *} \mathrm{p} \leq 0.01$, ns $=$ not significant. Positive values of 'side change to flow' reflect attraction to flow, negative values avoidance of flow. (b) Fish choice for lagoon or ocean water. Positive values of 'side change to lagoon' reflect preference for lagoon water; negative values would indicate preference for ocean water. Preference was tested statistically by a Wilcoxon's 2-tailed signed-rank test, ${ }^{*} \mathrm{p} \leq 0.05,{ }^{* *} \mathrm{p} \leq 0.01$, ns = not significant

\begin{tabular}{|c|c|c|c|c|c|}
\hline \multicolumn{6}{|c|}{ (a) Flow choice } \\
\hline Family & $\begin{array}{l}\text { Trapped, and } \\
\text { acclimated }\end{array}$ & $\mathrm{n}$ & $\begin{array}{l}\text { Side change to } \\
\text { flow } \% \pm \text { SEM }\end{array}$ & $\mathrm{p}$ & \\
\hline Apo & LL & 21 & $-7.9 \pm 4.7$ & 0.14 & ns \\
\hline Apo & $\mathrm{OO}$ & 2 & $21.0 \pm 5.5$ & 0.5 & ns \\
\hline Apo & LO & 8 & $1.6 \pm 9.2$ & 0.94 & ns \\
\hline Apo & OL & 2 & $8.0 \pm 8.9$ & 1.0 & ns \\
\hline Apo & $\mathrm{LL}+\mathrm{OO}$ & 23 & $-5.3 \pm 4.6$ & 0.36 & ns \\
\hline Apo & All & 33 & $2.8 \pm 3.9$ & 0.54 & ns \\
\hline Pom & All & 5 & $10.5 \pm 5.9$ & 0.13 & ns \\
\hline \multicolumn{6}{|c|}{ (b) Water choice } \\
\hline Family & $\begin{array}{l}\text { Trapped, and } \\
\text { acclimated }\end{array}$ & $\mathrm{n}$ & $\begin{array}{l}\text { Side change to } \\
\text { lagoon } \% \pm \text { SEM }\end{array}$ & $\Lambda^{\mathrm{p}}$ & \\
\hline Apo & LL & 21 & $9.5 \pm 3.9$ & 0.035 & $*$ \\
\hline Apo & $\mathrm{OO}$ & 2 & $11.8 \pm 0.7$ & 0.5 & ns \\
\hline Apo & LO & 8 & $4.2 \pm 11.0$ & 0.84 & ns \\
\hline Apo & OL & 2 & $3.2 \pm 5.1$ & 1.0 & ns \\
\hline Apo & $\mathrm{LL}+\mathrm{OO}$ & 23 & $9.7 \pm 3.6$ & 0.01 & $* *$ \\
\hline Apo & All & 33 & $8.0 \pm 3.6$ & 0.036 & $*$ \\
\hline Pom & All & 5 & $2.9 \pm 4.0$ & 0.63 & ns \\
\hline
\end{tabular}

trapped and acclimated under 3 different conditions: (1) caught in lagoon water using crest nets but acclimated in ocean water (LO), (2) caught in ocean water (light traps set hundreds of meters outside the reef, see Fig. 1) and acclimated in lagoon (OL) or (3) caught in and acclimated in ocean water $(\mathrm{OO})$. Lagoon preference ( 3 to $12 \%$, Table $1 \mathrm{~b}$ ) of these groups of fish was similar to the results described above for the (LL) group, suggesting that preference was not a result of trap location or induced by experimental acclimation. The greatest lagoon preference $(9.7 \pm 3.6 \%$, Wilcoxon's 2-tailed signed-rank test, $t=2.66, \mathrm{p}=0.01$ ) was shown by fish acclimated in the same water in which they were trapped (LL and OO).

Olfactory system. Microdissection and histology (Fig. 6) showed that settlement stage apogonids have well-developed noses with in- and outflow nares and accessory sacs typical for efficient nose ventilation

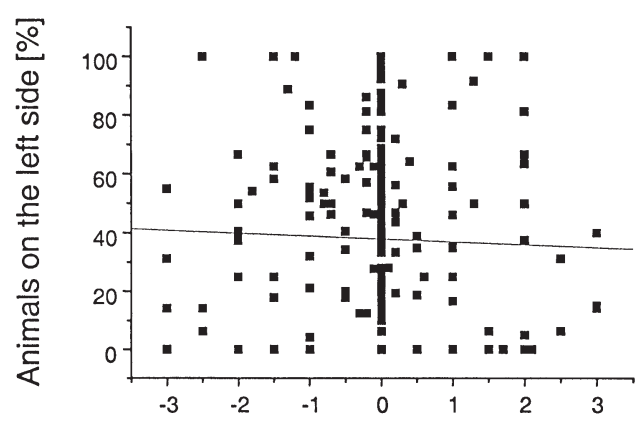

Temperature difference: left-right side $\left[{ }^{\circ} \mathrm{C}\right]$

Fig. 5. Animal distribution (percentage on left side) against temperature difference between water masses. Regression shows water temperature does not significantly affect side choice $\left(r^{2}=0.00098, y=0.377-0.01\right.$ temperature)

(Webb 1993). The 2 to 3 lamellae of the olfactory rosette are covered with sensory epithelium and are innervated by olfactory nerves connecting them to prominent olfactory bulbs, rostral-ventral to the telencephalon. Micropipetting a small dye cloud near an inflow naris of unanaesthetized apogonids (Apogon sp. 12 to $15 \mathrm{~mm} \mathrm{SL}$ ) showed that they sniff continuously: puffs of dye emerged from the outflow naris synchronous with 3 to $4 \mathrm{~Hz}$ gill ventilation movements. The presence of a well-developed nose and active sniffing suggest that olfaction provided the information needed for the lagoon odour preference in the behavioural experiments. Similarly, all other species we examined had well-developed noses; they include several species of pomacentrids, blennies and gobies.

\section{DISCUSSION}

The combined results of our 3 experimental approaches showed that olfactory cues should be seriously considered as candidates for helping pelagic stage larval reef fishes recruit back to the reef. During ebb tides we saw distinct turbidity plumes extend for several kilometers away from reefs; we tracked them by their temperature signature and showed that plumes generated during the heat of day float at the surface and that plumes generated during the night travel in deeper layers (Figs. $2 \& 3$ ). Thermal anomalies that relate to the advection of lagoon waters from reefs have been described (Wolanski \& Hamner 1988, Doherty et al. 1996). With the exception of Booth et al. (2000), however, there are few data on the spatial extent of these plumes. The spatial extent of the plumes we describe here are based on temperature measurements and on visual observations of turbidity. 
We cannot yet measure lagoon odour directly. However, turbidity particles sink and temperature gradients diminish faster than chemical gradients as a result of diffusion. This suggests that-depending on sensory-detection thresholds in larval fish-detectable odour concentrations may extend beyond the visual
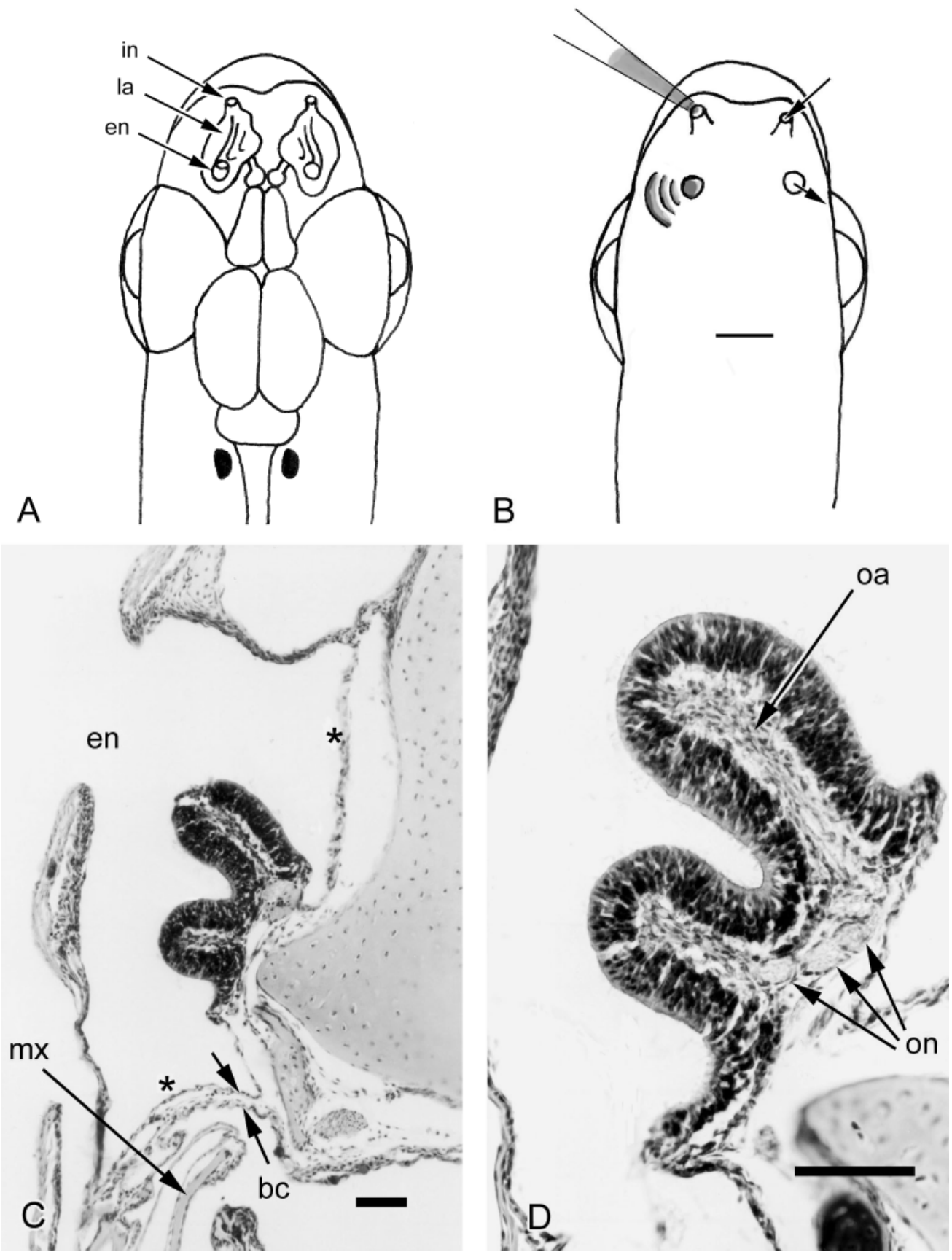

Fig. 6. (A) Dorsal view of olfactory organs (dotted lines) of a larval apogonid (12 mm SL) with incurrent (in) and excurrent (en) nares, and olfactory lamellae (la) lying in the olfactory sac between the nares. Noses are connected to the telencephalon via olfactory nerves and bulbs. (B) Dye (grey) applied around the incurrent naris with a micropipette emerged from the excurrent naris in distinct puffs corresponding to ventilatory jaw movements. Arrows on right side show the direction of net flow of the dye. Scale bar for A, B = $1 \mathrm{~mm}$. (C) Transverse histological section through the excurrent naris (en) showing the columnar olfactory epithelium over 2 lamellae. Two non-sensory diverticula $\left({ }^{*}\right)$ sit medio-dorsally and ventro-laterally to the olfactory epithelium. The position of the mobile maxillary bone ( $\mathrm{mx}$ ) and the thin membrane (opposing arrows) that sits between the lumen of the olfactory organ and the buccal cavity (bc) suggest a mechanism for olfactory ventilation. (D) Enlargement of the olfactory lamellae showing the darkly staining columnar olfactory epithelium, olfactory axons (oa) within each of the lamellae, and branches of the olfactory nerve (on), that project to the olfactory bulb. Scale bars for C, D =50 $\mu \mathrm{m}$ 
and thermal boundaries of the plumes. We assume that reef-specific odour flavours these plumes similar to home-streams used by anadromous fishes (Dittman et al. 1996).

Apogonids and all other settlement stage reef fishes we investigated had well-developed noses (Fig. 6) that would allow them to use olfactory information for many tasks, including reef odour recognition. Olfaction, rather than other chemical senses, is typically involved in far-field chemoreception tasks (Atema 1980, Basil et al. 2000). Apogonids demonstrated in choice tests to recognise different water masses by their odour and to prefer lagoon water to ocean water (Table 1b). This preference was independent of temperature differences (Fig. 5). Based on these results we hypothesise that settlement stage apogonids, as well as other reef fish, could use odour to relocate reefs after weeks 'at sea' either by active retention within the odour halo of the reef or by approaches from beyond the halo. Our hypothesis includes the possibility of homing back to the natal reef. We have no evidence to suggest whether fish ever leave the reef odour halo and need to relocate it from afar in order to settle back on the reef. Apogonids may attempt to stay near the reef whereas strong swimmers such as acanthurids would be good candidates for relocation behaviour from a greater distance as predicted by Armsworth (2000). Apogonids showed no significant preference for flow besides the upcurrent orientation presumably induced by optomotor response. Pomacentrids in 5 experiments, each with 7 to 13 conspecifics, showed a weak lagoon preference (Table 1b) and a stronger positive flow response (Table 1a). However, great variability and small sample size make these results no more than tantalizing suggestions deserving of further experimentation.

In addition to our experimental results we base the olfactory homing hypothesis of reef-fish larvae on the following considerations. Almost inevitably, lagoons produce significant chemical fingerprints characteristic of their biology (Montgomery et al. 2001, Kingsford et al. 2002). Thus, characteristic odour plumes continuously flavour the area surrounding the reef of origin at different water depths and at regular tidal intervals. Mixing is a slow process at these scales; this will allow lagoon water to remain identifiable in larger and then increasingly smaller patches for long times and distances. The result is a patchy odour halo around each reef, refreshed daily from initially distinct ebb plumes. The same slow mixing process disperses both lagoon odour and drifting fish eggs and larvae during the first days of their planktonic phase. Physical entrainment in lagoon water would provide a mechanism for imprinting on the odour of the natal lagoon similar to imprinting on host anemones in Amphiprion melanopus
(Arvedlund et al. 1999) and A. ocellaris (Arvedlund \& Nielsen 1996) and to juvenile salmon imprinting on odour cues in rivers on their way to the ocean (Dittman et al. 1996). While olfactory development in apogonids has not been studied, results from zebra fish (Hansen \& Zeiske 1993) and anemone fish (Arvedlund et al. 2000) show functional olfactory connections already at 2 and 7 d post-fertilisation, respectively.

As mixing continues, larvae develop greater locomotor capabilities (Fisher et al. 2000). This would allow them to cross patch boundaries and express choice between differently flavoured water masses. Unknown at this stage of development is whether they prefer ocean water (which would enhance dispersal) or lagoon water (which would facilitate retention near the reef), or whether they care at all. Finally, in settling-stage apogonids our results show well-developed olfaction and, in lagoon versus ocean choice tests, significant preference for lagoon water. Armsworth (2000) makes a good theoretical case for rather weak swimmers such as apogonids to remain near the reef. Our results provide a possible mechanism for retention: apogonids and other species in the weak-swimmer category initially would remain entrained in lagoon water and later, as odour plume-mixing continues, use their increasing mobility to avoid ocean water. Finally, orientation to reefs could be achieved with eddychemotaxis (Atema 1996) using the fine scale eddy structure of lagoon-flavoured ebb plumes to help them navigate back to the reef's close vicinity from where nocturnal flood tides carry them over the crest into the lagoon. In this process odour is thought to be one of several sensory cues involved; detection of small-scale flow and acoustic and magnetic vectors may be important, as well as choice of water depth for entrainment in favourable currents (Fisher et al. 2000, Job \& Bellwood 2000, Armsworth 2001, Armsworth et al. 2001, reviews by Montgomery et al. 2001, Kingsford et al. 2002). Among reef fish larvae, apogonids tend to be found at greater depths (Fisher \& Bellwood 2002) but it is not known how this relates to specific current regimes.

In our flume tests not all fish could express a choice because many did not cross the boundary between water masses in the 3 min treatment time allotted. This may be due in part to their optomotor behaviour that keeps them oriented up-current and holding station. The resulting almost $10 \%$ change toward lagoon water in 3 min leads us to believe that, given more testing time, more if not all fish would be collecting in lagoon water. In the open ocean, without fixed visual reference objects, fish would not express optomotor behaviour. Instead, they would use their eyes and other senses to hunt for food and avoid predators. Both activities would lead to regular encounters with lagoon/ ocean water boundaries where reef plumes mix with 
ocean water. Larvae with a preference for lagoon odour can express this choice at every patch boundary. The predicted result is that many of those animals would be found in patches of lagoon water.

Reliance on olfactory information became even more compelling when we found that differences in temperature did not affect choice between water with different odours (Fig. 5). This result was at first surprising since temperature is a good indicator of differences between oceanic water masses. However, reef plumes can be both warmer $\left(0.5\right.$ to $\left.2^{\circ} \mathrm{C}\right)$ and colder $\left(0.5\right.$ to $\left.1^{\circ} \mathrm{C}\right)$ than surrounding ocean water (Fig. 2). This leaves temperature by itself unreliable for identification of lagoon water. However, temperature difference may still be a useful trigger to start paying attention to odour signals. Close observation of larval behaviour at the boundary between water masses in the flume showed several instances of fish 'bouncing off' the invisible wall. They did this from either side suggesting that they noticed the boundary but did not prefer the other side.

In these flume experiments it is not likely that senses other than chemical senses played a role in the demonstrated lagoon water choice. From the fishes' perspective, their horizontal view of the vertical boundary between water masses against the dark brown plywood sides of the flume and the low light levels in which experiments were run would render visual cues unlikely for water mass discrimination. However, these fish have good eyes (Job \& Bellwood 2000) and in all experiments showed a strong optomotor response, holding station and orienting into the current. Flow information from lateral line (Montgomery et al. 1997) and otolith organs cannot have contributed to choice, since flow conditions, both mean flow and turbulence, were equal between sides, and sides were also alternated for lagoon water presentation. Sound, an orientation signal suggested for field release conditions (Leis et al. 1996), light-trap catch experiments (Tolimieri et al. 2000), and magnetic information (Walker et al. 1997) possible over large spatial scales in the field, are all excluded by the side-switching experimental design. In natural plumes, small-scale flow detection by frontal-lateral line canals (not pictured, but clearly visible in dissection and histological sections) could be useful in concert with olfactory information to recognise shear flow at odour plume and patch boundaries (Atema 1996).

The implications of our findings suggest that lagoon odour recognition and preference could be used by larval fish to facilitate retention within a reef's tidal odour halo, or wake (Lobel \& Robinson 1986). It is also possible that some species could use chemical recognition of lagoon water to navigate along odour plumes to locate reefs, perhaps their natal reefs, for settlement.
Ebb plumes could attract fish and bring them toward the reef when the tide reverses. The plumes and halos would also expand considerably the target size for animals coming in from farther away. Given biological differences between reefs it would not be surprising to find recognisable differences between reef odours. Odour candidates include the considerable release of mucilage from corals (Johannes 1967, Deacon 1979, Crossland 1987). Although it is unlikely that olfaction is the only sense that presettlement fishes use to respond to their environment (Montgomery et al. 2001, Kingsford et al. 2002), chemical cues and odour imprinting hold the promise of specificity that fish could use to discriminate among reefs, including their natal reef. Preferential settlement on natal reefs would predict genetic substructuring of populations along the Great Barrier Reef. If apogonids and other weak swimmers indeed emphasise retention near the natal reef then they might show greater genetic substructuring than fish that swim over greater distances. The olfactory sensitivity of fishes and its potential role in navigation also emphasises the necessity for maintaining good water quality in reef environments. Finally, behavioural responses to reef-odour cues should be included in models of larval retention and dispersal.

Acknowledgements. We thank Ben Stewart for assistance in the field and Ben and Jo Browne for assistance with the tank experiments. We thank Dr. Jacqueline Webb for histological examination of apogonid noses (Fig. 6C,D) and critical reading of the manuscript.

\section{LITERATURE CITED}

Armsworth PR (2000) Modelling the swimming response of late stage larval reef fish to different stimuli. Mar Ecol Prog Ser 195:231-247

Armsworth PR (2001) Directed motion in the sea: efficient swimming by reef fish larvae. J Theor Biol 210:81-91

Armsworth PR, James MK, Bode L (2001) When to press on or turn back: dispersal strategies for reef fish larvae. Am Nat 157:434-450

Arvedlund M, Nielsen LE (1996) Do anemone fish Amphiprion ocellaris (Pisces: Pomacentridae) imprint themselves to their host sea anemone Heteractis magnifica (Anthozoa: Actinidae)? Ethology 102:197-211

Arvedlund M, McCormick MI, Fautin DG, Bildsøe M (1999) Host recognition and possible imprinting in the anemonefish Amphiprion melanopus (Pisces: Pomacentridae). Mar Ecol Prog Ser 188:207-218

Arvedlund M, Larsen K, Winsor H (2000) The embryonic development of the olfactory system in Amphiprion melanopus (Perciformes: Pomacentridae) related to the host imprinting hypothesis. J Mar Biol Assoc UK 80: 1103-1109

Atema J (1980) Smelling and tasting underwater. Oceanus 23: $4-18$

Atema J (1996) Eddy chemotaxis and odor landscapes: exploration of nature with animal sensors. Biol Bull 191:129-138

Basil JA, Hanlon RT, Sheikh SI, Atema J (2000) Three- 
dimensional odor tracking by Nautilus pompilius. J Exp Biol 203:1409-1414

Boehlert GW, Mundy BC (1993) Ichthyoplankton assemblages at seamounts and oceanic islands. Bull Mar Sci 53: 336-361

Booth J, Kingsford MJ, Doherty PJ, Berretta BA (2000) Recruitment of damselfishes in One Tree Island lagoon: persistent interannual spatial patterns. Mar Ecol Prog Ser 202:212-230

Cowen RK, Lwiza KMM, Sponaugle S, Paris SB, Olson DB (2000) Connectivity of marine populations: open or closed? Science 287:857-859

Crossland CJ (1987) In situ release of mucus and DOC-lipid from the corals Acropora variabilis and Stylophora pistillata in different light regimes. Coral Reefs 6:35-42

Deacon EL (1979) The role of coral mucus in reducing wind drag over coral reefs. Boundary-Layer Meteorol 17:517-521

Dittman AH, Quinn TP, Nevitt GA (1996) Timing of imprinting to natural and artificial odors by coho salmon (Oncorhynchus kisutch). Can J Fish Aquat Sci 53:434-442

Doherty PJ (1987) Light-traps: selective but useful devices for quantifying the distributions and abundance of larval fishes. Bull Mar Sci 41:423-431

Doherty PJ, Kingsford MJ, Booth D, Carleton J (1996) Habitat selection before settlement by Pomacentrus coelestis. Mar Freshw Res 47:391-399

Elliott JK, Elliott JM, Mariscal RN (1995) Host selection, location, and association behaviours of anemonefishes in field settlement experiments. Mar Biol 122:377-390

Finn MD, Kingsford MJ (1996) Two-phase recruitment of apogonids (pisces) on the Great Barrier Reef. Mar Freshw Res 47:423-432

Fisher R, Bellwood DR (2002) A light trap design for stratumspecific sampling of reef fish larvae. J Exp Mar Biol Ecol 269:27-37

Fisher R, Bellwood DR, Job SD (2000) Development of swimming abilities in reef fish larvae. Mar Ecol Prog Ser 202: 163-173

Hall (1986) The role of movement and tissue interaction in the development and growth of bone and secondary cartilage in the clavicle of the embryonic chicken. J Embryol Exp Morphol 93:133-152

Hansen A, Zeiske E (1993) Development of the olfactory organ in the zebrafish, Brachydanio rerio. J Comp Neurol 333:289-300

Job S, Bellwood DR (2000) Light sensitivity in larval fishes: implications for vertical zonation in the pelagic zone. Limnol Oceanogr 45:362-371

Johannes RE (1967) Ecology of organic aggregates in the vicinity of a coral reef. Limnol Oceanogr 12:189-195

Jones GP, Milicich MJ, Emslie MJ, Lunow C (1999) Selfrecruitment in a coral reef fish population. Nature 402: 802-804

Kingsford MJ (1988) The early life history of fish in coastal waters of northern New Zealand: a review. NZ J Mar Freshw Res 22:463-479

Kingsford MJ (2001) Diel patterns of abundance of presettlement reef fishes and pelagic larvae on a coral reef. Mar Biol 138:853-867

Kingsford MJ, Finn M (1997) The influence of phase of the moon and physical processes on the input of presettlement fishes to coral reefs. J Fish Biol 51(Suppl A):176-205

Kingsford MJ, Leis J, Shanks A, Lindeman K, Morgan S, Pineda J (2002) Sensory environments, larval abilities and local self-recruitment. Bull Mar Sci (in press)

Leis JM (1991) The pelagic stage of reef fishes: the larval biology of coral reef fishes. In: Sale PF (ed) The ecology of fishes on coral reefs. Academic Press, New York, p $183-230$

Leis JM, Carson-Ewart BM (1997) In situ swimming speeds of the late pelagic larvae of some Indo-Pacific coral-reef fishes. Mar Ecol Prog Ser 159:165-174

Leis J, Rennis DS (1983) The larvae of Indo-Pacific coral reef fishes. New South Wales University Press, Sydney

Leis JM, Sweatman HPA, Reader SE (1996) What the pelagic stages of coral reef fishes are doing out in blue water: daytime field observations of larval behavioural capabilities. Mar Freshw Res 47:401-411

Lobel PS, Robinson AR (1986) Transport and entrapment of fish larvae by mesoscale eddies and currents in Hawaiian waters. Deep-Sea Res 33:483-500

Marnane MJ (2000) Site fidelity and homing behaviour in coral reef cardinalfishes. J Fish Biol 57:1590-1600

Montgomery JC, Baker CF, Carton AG (1997) The lateral line can mediate rheotaxis in fish. Nature 389:960-963

Montgomery JC, Tolimieri N, Haine OS (2001) Active habitat selection by pre-settlement reef fishes. Fish Fish 2: 261-277

Planes S, Bonhomme F, Galzin R (1993) Genetic structure of Dascyllus aruanus populations in French Polynesia. Mar Biol 117:665-674

Robertson DR (2001) Population maintenance among tropical reef fishes: inferences from small-island endemics. Proc Natl Acad Sci USA 98:5667-5670

SAS Institute (1995) JMP statistics and graphics guide (Version 3.1). Cary, NC

Stobutzki I, Bellwood DR (1997) Sustained swimming abilities of the late pelagic stages of coral reef fishes. Mar Ecol Prog Ser 149:35-41

Stobutzki IC, Bellwood DR (1998) Nocturnal orientation to reefs by late pelagic stage coral reef fishes. Coral Reefs 17: 103-110

Swearer SE, Caselle JE, Lea DW, Warner RR (1999) Larval retention and recruitment in an island population of a coral-reef fish. Nature 402:799-802

Sweatman H (1988) Field evidence that settling coral reef fish larvae detect resident fishes using dissolved chemical cues. J Exp Mar Biol Ecol 124:163-174

Tolimieri N, Jeffs A, Montgomery JC (2000) Ambient sound as a cue for navigation by pelagic larvae of reef fishes. Mar Ecol Prog Ser 207:219-224

Vagelli A (1999) The reproductive biology and early ontogeny of the mouthbrooding Banggai cardinalfish, Pterapogon kauderni (Perciformes, Apogonidae). Environ Biol Fish 56: 79-92

Walker MM, Diebel CV, Haugh CV, Pankhurst PM, Montgomery JC, Green CR (1997) Structure and function of the vertebrate magnetic sense. Nature 390:371-376

Webb JF (1993) The accessory nasal sacs of flatfishes: systematic significance and functional implications. Bull Mar Sci 52:541-553

Williams DM, Wolanski E, Andrews JC (1984) Transport mechanisms and the potential movement of planktonic larvae in the central region of the Great Barrier Reef. Coral Reefs 3:229-236

Wolanski E (1994) Physical oceanographic processes of the Great Barrier Reef. CRC Press, Boca Raton, FL

Wolanski E, Hamner WH (1988) Topographically controlled fronts in the ocean and their biological influence. Science 241:171-181

Wolanski E, Doherty P, Carleton J (1997) Directional swimming of fish larvae determines connectivity of fish populations on the Great Barrier Reef. Naturwissenschaften 84: 262-268 